This item was submitted to Loughborough's Research Repository by the author.

Items in Figshare are protected by copyright, with all rights reserved, unless otherwise indicated.

\title{
Shear strength and fracture toughness of carbon fibre/epoxy interface: effect of surface treatment
}

PLEASE CITE THE PUBLISHED VERSION

http://dx.doi.org/10.1016/j.matdes.2015.07.104

PUBLISHER

(C) Elsevier Ltd.

VERSION

SMUR (Submitted Manuscript Under Review)

\section{PUBLISHER STATEMENT}

This work is made available according to the conditions of the Creative Commons Attribution-NonCommercialNoDerivatives 4.0 International (CC BY-NC-ND 4.0) licence. Full details of this licence are available at: https://creativecommons.org/licenses/by-nc-nd/4.0/

\section{LICENCE}

CC BY-NC-ND 4.0

\section{REPOSITORY RECORD}

Wang, Chen, Xianbai Ji, Anish Roy, Vadim V. Silberschmidt, and Zhong Chen. 2019. "Shear Strength and Fracture Toughness of Carbon Fibre/epoxy Interface: Effect of Surface Treatment”. figshare. https://hdl.handle.net/2134/19466. 


\title{
Shear Strength and Fracture Toughness of Carbon Fibre/epoxy interface: Effect of Surface Treatment
}

\author{
Chen Wang ${ }^{1,2,3}$, Xianbai $\mathrm{Ji}^{4}$, Anish Roy ${ }^{3}$, Vadim V. Silberschmidt ${ }^{3}$, Zhong Chen ${ }^{1, *}$ \\ ${ }^{1}$ School of Materials Science and Engineering, Nanyang Technological University, 50 \\ Nanyang Avenue, 639798, Singapore \\ ${ }^{2}$ Institute for Sports Research, Nanyang Technological University, 50 Nanyang Avenue, \\ 639798, Singapore \\ ${ }^{3}$ Wolfson School of Mechanical and Manufacturing Engineering, Loughborough University, \\ Leicestershire, LE113TU, U.K. \\ ${ }^{4}$ Temasek Laboratories@NTU, 50 Nanyang Drive, 637553, Singapore
}

\begin{abstract}
:
Braided textile-reinforced composites have become increasingly attractive as protection materials for various applications, including sports.,In such applications it is crucial to maintain both strong adhesion at fibre-matrix interface and high interfacial fracture toughness, which influence mechanical performance of composites as well as their energy-absorption capacity. Surface treatment of reinforcing fibres has been widely used to achieve satisfactory fibre-matrix adhesion. However, most studies till date focused on the overall composite performance rather than on the interface properties of a single fibre/epoxy system. In this study, carbon fibres were treated by mixed acids for different durations, and resulting adhesion strength at the interface between them and epoxy resin as well as their tensile strength were measured in a microbond and microtensile tests, respectively. The interfacial fracture toughness was also analysed. The results show that after an optimum 15-30 min surface treatment, both interfacial shear strength and fracture toughness of the interface were improved alongside with an increased tensile strength of single fibre. However, a prolonged surface treatment resulted in a reduction of both fibre tensile strength and fracture toughness of the interface due to induced surface damage.
\end{abstract}

\footnotetext{
*Corresponding author’s email: ASZChen@ntu.edu.sg
} 
Key words: carbon fibre; surface treatment; interfacial shear strength; fracture toughness; tensile strength; microbond test

\section{Introduction}

Braided textile-reinforced composites have received considerable attention in recent years as protection materials in various applications, including sports (i.a. helmets and shin guards) [1]. Such composites exhibit high structural stability, excellent damage tolerance and energy absorption due to the yarn interlacing. In an impact event the kinetic energy is dissipated through a number of mechanisms, including deformation of secondary yarns, primary yarn breakage and energy spent to overcome inter-yarn friction [2]. The ease of incorporating different types of yarns enables one to manufacture composites with a wide range mechanical and physical property. In such composites, the interaction of yarns as well as stress distribution and energy dissipation in them are affected by microscopic structures and the adhesion between of the fibres and matrix in the yarn.

It is known that the carbon fibre-reinforced composites (CFRCs) show poor interfacial adhesion between fibres and epoxy matrix, due to a chemically inert surface and low surface energy of the carbon fibre (CF). Hence, extensive studies have been undertaken to improve the interfacial adhesion with different surface treatment methods, including gaseous, solution, electrochemical, catalytic, oxidative etching, polymer coating (sizing) and plasma-activation methods [3-6]. Amongst these, a use of mixed sulphuric and nitric acids $\left(\mathrm{H}_{2} \mathrm{SO}_{4} / \mathrm{HNO}_{3}\right)$ are increasingly adopted to functionalize carbon fibres [4-6]. Although interfacial shear strength of the composites increases after surface treatment of fibres, their impact resistance is known to decrease in some cases. A major challenge in composite manufacture is to obtain CFRCs with a combination of high impact resistance and strong interfacial adhesion. Admittedly, 
some studies have dealt with this subject; however, there is limited research into the effect of surface treatment on interfacial toughness of CFRCs. Furthermore, most studies addressed only the influence of surface treatment on macroscopic properties of composites, fibre yarns or plies, rather than individual fibres in the yarn. The relationship between the interfacial shear strength and toughness is not well understood, specifically in microscale. $[7,8]$. Therefore, it is crucial to investigate the influence of surface treatment on the tensile strength of single fibres, and techniques used to maintain fibre-epoxy interfacial shear strength and fracture toughness concurrently [9].

Compared to tensile-strength measurements, it is difficult to assess interfacial shear strength between a single fibre and resin. At present, there are primarily four techniques that have been developed over the years, namely fibre pull-out, microbond, fibre push-in and fragmentation tests [10]. Among them, the microbond test, which was developed by Miller et al. [11] is preferred thanks to its simplicity and overall repeatability of experimental results. With regard to evaluating interfacial fracture toughness, a quantitative characterization of properties of the fiber-matrix interface requires an appropriate approach, which should take into account the actual mechanism of interfacial failure as well as non-uniformity of a local stress distribution at the interface. For this purpose, numerous models describing stress distributions and interfacial failure in fiber-matrix systems were proposed. Several stress-analysis schemes have been used to assess the energy release rate $G$ for initiation of an interfacial crack in a microbond specimen. A comprehensive theory was developed by Nairn et al. [12-14]. The model assumes that the debonding zone extends when the energy release rate reaches its critical value $G_{\text {Ic }}$; thus, $G_{\text {Ic }}$ is equal to the interfacial fracture toughness. The value of $G_{\text {Ic }}$ reflects the energy-dissipation capacity during the debonding process of fibre-matrix system. Recently, the model was further modified by Scheer et al. [14] and applied to both 
experimental and numerical finite-element (FE) analysis mainly for glass and Kevlar fibres. In our study, the method will be applied for the carbon fibre/epoxy system.

When using mixed sulphuric and nitric acids to modify carbon fibres (CFs), the time of treatment is of considerable importance. Based on current studies, the suggested time of surface treatment varies from a few minutes to several hours for different applications. Han et al. [3] pointed out that the tensile strength of CF decreased extensively after two hours of surface treatment. Langston et al. [15] stated that the best functionalization efficiency and highest oxygen concentration was obtained with the surface treatment of $80 \mathrm{~min}$. Wang et al. [16] found that 15 min was preferred to pursue best electrical conductivity of CFs. In this study, carbon fibres were treated by mixed acids, and the surface treatment time was optimized by balancing the levels of tensile strength of fibre, adhesive strength and fracture toughness of CF/epoxy interface.

\section{Experimental}

\subsection{Materials and Surface Treatment}

The PAN (Polyacrylonitrile)-based AKSAca A-42 carbon fibre with bulk density of 1.78 $\mathrm{g} / \mathrm{cm}^{3}$ and yield of $800 \mathrm{~g} / \mathrm{km}$ was used. Bakelite ${ }^{\circledR}$ EPR-L20 epoxy resin was used as matrix material. The resin was mixed with EPH-960 hardener at the weight ratio of 100:35 and the mixture was then degassed for approximately 30 minutes before curing. The acid surface treatment employed a 3:1 (v/v) mixture of concentrated $\mathrm{H}_{2} \mathrm{SO}_{4}$ and $\mathrm{HNO}_{3}$, with sonication at $60^{\circ} \mathrm{C}$. During the treatment, A-42 carbon fibre was added to $60 \mathrm{ml}$ of the mixed acid solution in a beaker. The treatment was carried out at different controlled times from 15 min to $60 \mathrm{~min}$ at an interval of 15 min. The treated fibres were then placed in another beaker and washed several times in DI water until the $\mathrm{pH}$ level was around 7. Washing removed all water-soluble 
$\mathrm{N}$ - and S-oxides, replacing them with hydroxyl groups through ion exchange; though direct $\mathrm{N}$ - and S-bonded were retained [4].

\subsection{Testing and Characterisation}

A microbond and single-fibre tensile tests were carried out using an in-house developed tester equipped with a 250 gram-force (gf) load cell [17]. In a microbond test, a fibre filament was first mounted onto a paper holder. Next, epoxy resin droplets were applied on the fibre and cured at room temperature for 24 hrs followed by post-curing at $60^{\circ} \mathrm{C}$ for 15 hrs. As shown in Figure 1, in the microbond test, the fibre was pulled at a speed of $1 \mu \mathrm{m} / \mathrm{s}$ while the epoxy droplet was constrained from translating along the loading directions by a microvise jaw
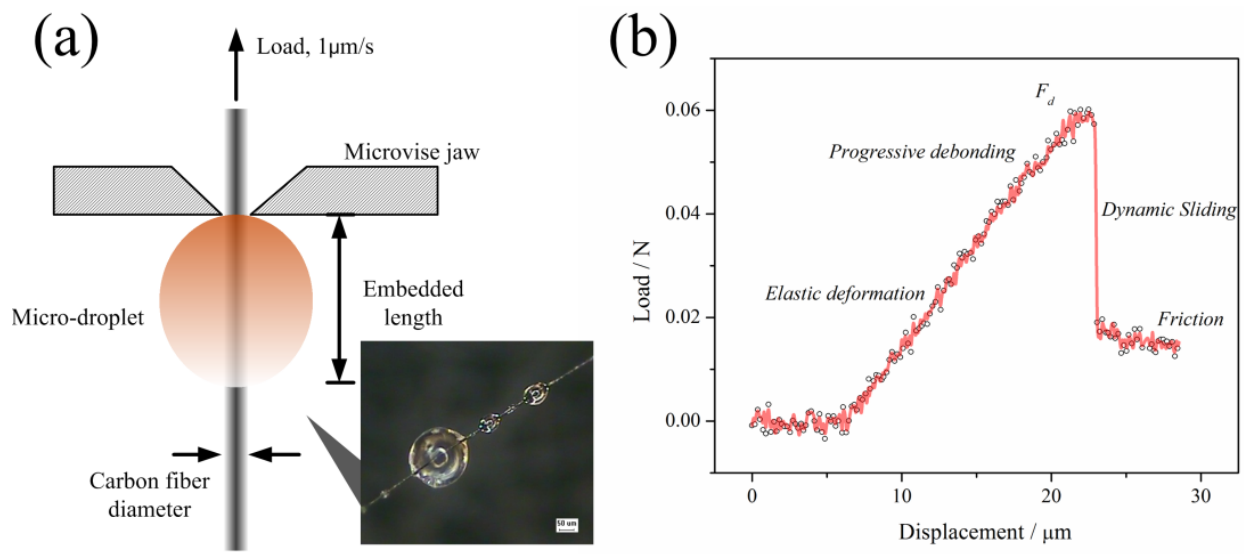

Figure 1 (a) Schematic of microbond test; (b) typical load-displacement curve

All specimens were checked under the microscope to observe geometry and embedded length of the droplet. Samples with defects (such as kink bands on the fibre or obvious lack of symmetry of the droplet) were rejected. Ideal epoxy droplet length was around 80-200 $\mu \mathrm{m}$. This ensures that the required pullout forces exceeds the breaking strength of the fibre. The force needed to pull the fibre out of the resin was then determined. Assuming that the measured force is equal to a shearing force that is applied to the entire interface and 
distributed uniformly, the apparent interfacial shear strength $\left(\right.$ IFSS $_{\text {app }}$ ) of carbon//epoxy interface is determined as

$$
I F S S_{a p p}=\frac{F_{d}}{\pi D l}
$$

where $F_{d}$ is the peak pull-out force, $D$ isthe fibre diameter and $l$ is the embedded length of the fibre.

During the experiment, as the fibre was pulled, the epoxy droplet on the fibre first contacted the microvise, which transferred the load from the fibre to the fibre/epoxy interface. Postengagement, the initial load-displacement behaviour was nearly linear as elastic energy accumulated followed by a sudden drop in force (see a typical load-displacement plot in Figure 1(b)). The stored energy was dissipated with the initiation of an interfacial crack. The load did not drop to zero after its peak value as frictional forces were present.

Furthermore, neglecting thermal effects, $G_{\text {Ic }}$ can be calculated by [14]:

$$
F_{d}=\pi r_{1}^{2} \sqrt{\frac{2 G_{\mathrm{Ic}}}{r_{1} C_{33 s}}}
$$

where

$$
C_{33 s}=\frac{1}{2}\left(\frac{1}{E_{1}}+\frac{V_{1}}{V_{2} E_{2}}\right) .
$$

In Equation $3, E_{1}, E_{2}, G_{1}, G_{2}, V_{1}, V_{2}$, and $r_{1}$ are the Young's modulus of fibre, the Young's modulus of epoxy droplet, the shear modulus of fibre, the shear modulus of epoxy droplet, the volume fraction of fibres, the volume fraction of matrix droplet $\left(=1-V_{1}\right)$ and the diameter of fibre, respectively. Herein, all the parameters were obtained from experiments.

Next, tensile tests were carried out, in which single filaments were tested following ASTM C1557-03 standard. The single-filament specimen was prepared by mounting a single carbon fibre onto a paper holder using cyanoacrylate glue. The sample was placed in the grips of the 
micro-tester equipped with a 250 gf load cell. Both sides of the paper holder were cut by scissors before testing, leaving the fibre between the grips intact. Single-filament specimens with gauge lengths of 5, 10, 15 and $20 \mathrm{~mm}$ were tested at the speed of $1 \mu \mathrm{m} / \mathrm{s}$. A minimum of 10 specimens were tested for each gauge length. It should be noted that the strain were measured based on the grip movement of the tensile machine. Therefore, the system's compliance correction had to be performed following the procedure described in ASTM C1577-03. In this study the system's compliance $\left(C_{s}\right)$ was determined to be $0.022 \mathrm{~mm} / \mathrm{N}$ by plotting $\Delta L / F$ ( $=C_{a}$, apparent compliance) against $l_{0} / A$, as shown in Figure 2; here, $\Delta L$ is the grip movement measured with the machine, $F$ is the failure load, $A$ is the initial crosssectional area of the carbon fibre and $l_{0}$ is the gauge length of the sample. All the results presented in this study were calibrated accounting for compliance.

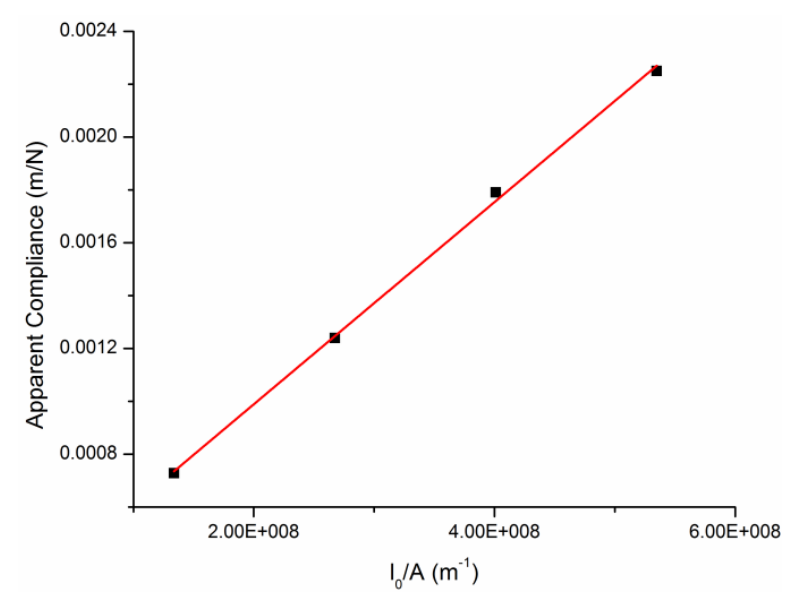

Figure 2 Apparent compliance vs. gauge length normalised with cross-sectional area of carbon fibre

The diameter and surface topography of carbon fibers were characterized using a fieldemission scanning electron microscope (FE-SEM, JEOL JSM 6700F) with an emission current of $12 \mu \mathrm{A}$ and accelerating voltage of $5 \mathrm{kV}$. The geometry of epoxy droplets was observed with a Zeiss stereo microscope. The functional groups on the surface of carbon fibers were checked with Fourier transform infrared spectroscopy (FTIR). The morphologies 
of CFs after acid etching were examined with an atomic force microscope (AFM) Cypher S with the scan rate of $1 \mathrm{~Hz}$.

\section{Results and Discussion}

The specimens were examined by FE-SEM to determine changes their diameters caused by the acid treatment (Figure 3). Their surface shows grooves along the longitudinal direction of fibres. It was found that the number of shallow grooves increased with an increase in treatment time. The fibre diameter, measured to be $7.3 \pm 0.4 \mu \mathrm{m}$, did not alter after acid treatment.

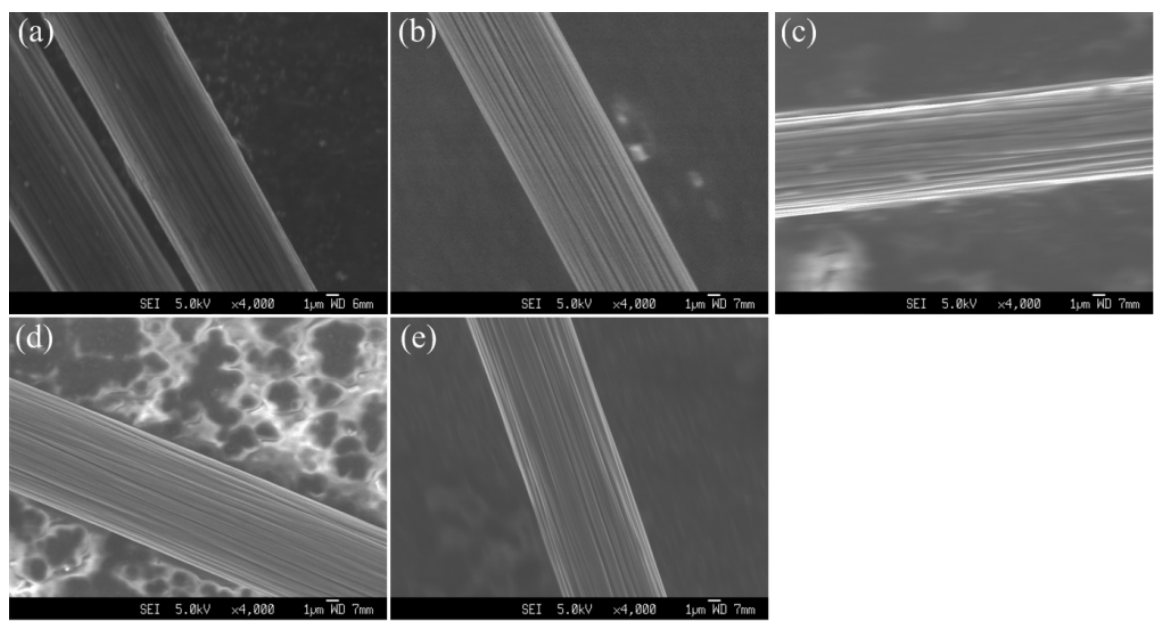

Figure 3 FE-SEM topographies of A-42 carbon fibres with oxidation treatment of different durations: (a) $0 \mathrm{~min}$; (b) $15 \mathrm{~min}$; (c) $30 \mathrm{~min}$; (d) $45 \mathrm{~min}$; (e) 60

In a microbond test, the debonding force $F_{d}$ is proportional to the embedded length of the epoxy droplet $l$, according to Equation 1. Therefore, despite the observed experimental scatter, the apparent IFSS can be calculated from the slope of linear regression of $F_{d} v s . l$ plot, as shown in Figure 4. The IFSS $a$ app of the studied carbon//epoxy interface without surface treatment was determined to be $28.12 \mathrm{MPa}$, in a reasonable agreement with other documented data [8]. After the surface treatment, the magnitudes of IFSS $_{\text {app }}$ were enhanced as shown in 
Figure 5 and Table 1. After one hour of the suggested treatment, the level of IFSS $_{\text {app }}$ increases by $29.2 \%$.
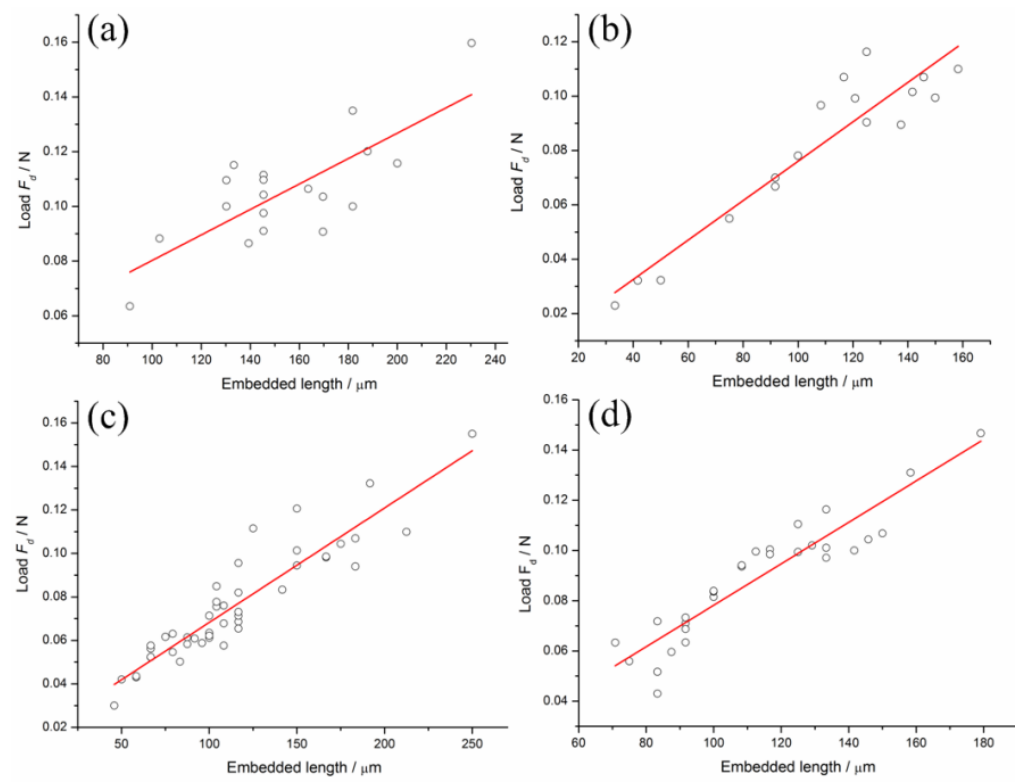

Figure 4 Experimental data and linear regression for measured debonding force and embedded length for various surface treatment times: (a) 15 min; (b) 30 min; (c) 45 min; (d) $60 \mathrm{~min}$

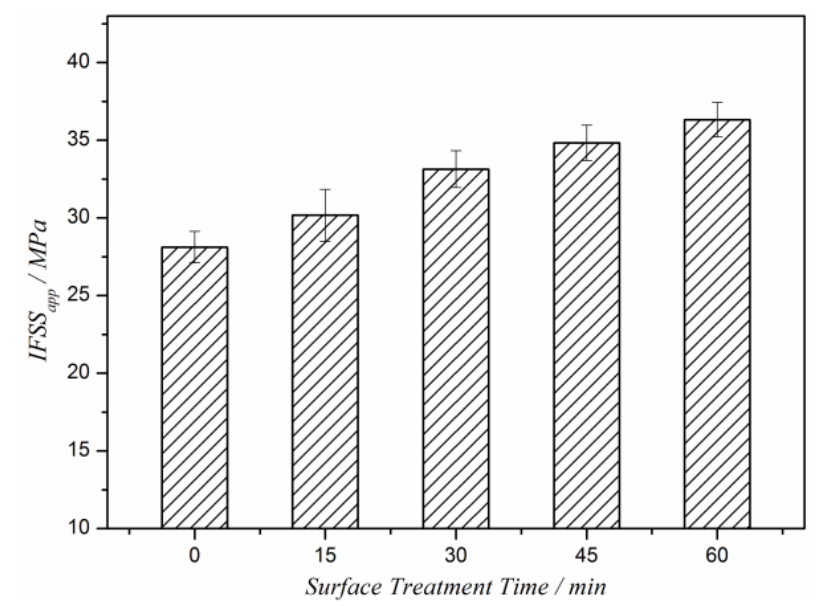

Figure 5 Effect of surface treatment on interfacial shear strength between single fibre and epoxy

Table 1 Interfacial shear strength before and after surface treatment 


\begin{tabular}{cccccc}
\hline $\begin{array}{c}\text { Treatment } \\
\text { time (min) }\end{array}$ & $\begin{array}{c}\text { Average } \\
\text { IFSS }( \pm \text { std. } \\
\text { dev.) }(\mathrm{MPa})\end{array}$ & $\begin{array}{c}\text { Coefficient of } \\
\text { variation (\%) }\end{array}$ & $\begin{array}{c}95 \% \\
\text { Confidence } \\
\text { interval } \\
(\mathrm{MPa})\end{array}$ & $\begin{array}{c}90 \% \\
\text { Confidence } \\
\text { interval } \\
(\mathrm{MPa})\end{array}$ & Increase (\%) \\
\hline 0 & $28.12 \pm 2.74$ & 9.8 & 1.02 & 0.85 & 0 \\
15 & $30.18 \pm 3.41$ & 11.3 & 1.67 & 1.40 & 7.3 \\
30 & $33.14 \pm 2.18$ & 6.6 & 1.19 & 1.00 & 17.8 \\
45 & $34.84 \pm 2.60$ & 7.5 & 1.14 & 0.96 & 23.9 \\
60 & $36.33 \pm 2.98$ & 8.2 & 1.10 & 0.93 & 29.2 \\
\hline
\end{tabular}

The effects of surface treatment on the average tensile strength of fibre filaments was systematically studied with four different gauge lengths and shown in Figure 6. In singlefilament tensile test, the ultimate strength of carbon fibre decreases with an increase in the fibre's gauge length. The gauge-length effect is mainly attributed to the presence of flaws in the fibre. With an increase in gauge length the probability of encountering defects increases, lowering correspondently the observed tensile strength. Apparently, the suggested surface treatment is not capable to eliminate fully the gauge length effect (partly due to the presence of internal flaws that can be cured only by heat treatment above $1200^{\circ} \mathrm{C}$ [18]); still, it can alleviate it with treatment of 15 min and 30 min duration (Fig. 6a). In contrast, the gaugelength effect was exacerbated when the acid treatment extended to $45 \mathrm{~min}$ and $60 \mathrm{~min}$.
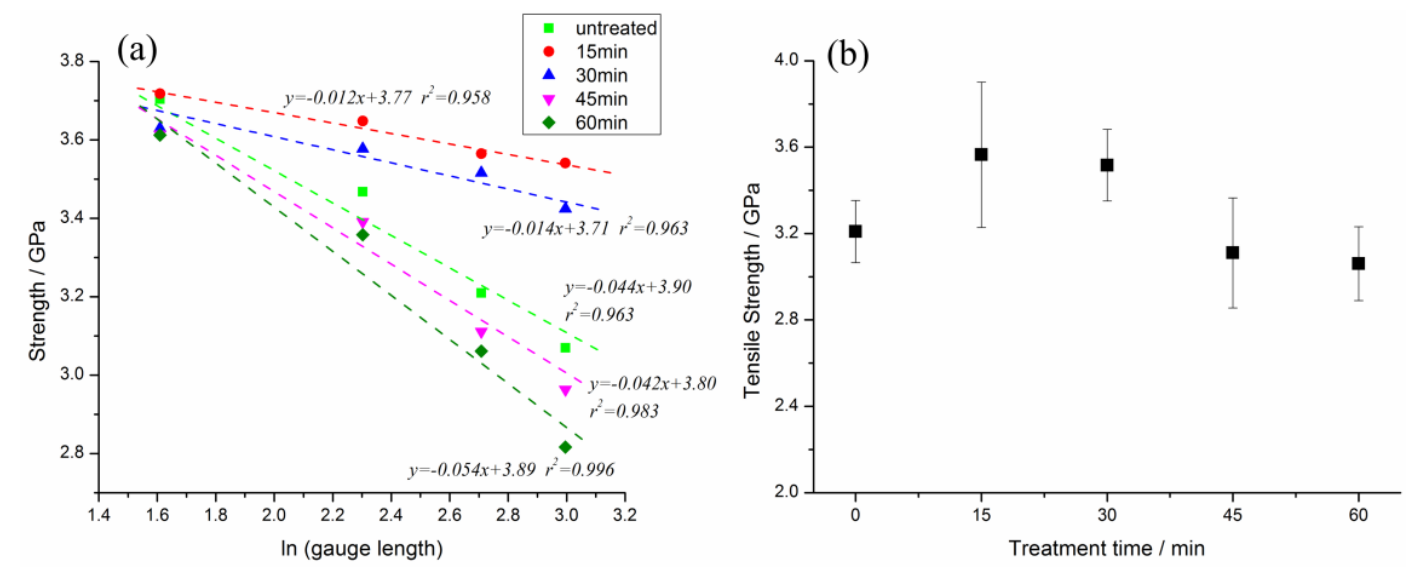
Figure 6 Effect of gauge length (a) and surface treatment time (b) on tensile strength of A-42 carbon fibres

Importantly, the treatment affect beneficially the tensile strength of CFs. Figure 6 (b) depicts the relationship between the ultimate tensile strength and the time of treatment with acids, taking samples with the gauge length of $15 \mathrm{~mm}$ as example. It is obvious that the tensile strength of A-42 carbon fibres peaks at 15 min of acid treatment and then decreases, with subsequent flattenning. The degradation of tensile strength implies that additional surface defects were introduced by excessive oxidation, increasing the probability of fibre damage and fragmentation [18]. Therefore, we conclude that the moderate acid treatment can improve tensile strength of CFs by removing the weak (damaged) surface layer and existing impurities from the surface. However, over-oxidation should be avoided. Average values of the Young's modulus in the longitudinal direction $E_{1}$ of A-42 carbon fibre at different gauge lengths are shown in Figure 7. Overall, the Young's modulus decreased slightly after acid oxidation; the decline is due to acid etching that removes microvoids and the amorphous outer layer from the carbon fibre surface [15]. Some researchers mentioned also another potential mechanism of the modulus variation: a change in the orientation of crystallites in CFs [19].

Here, the average values of the Young's modulus were further used to calculate the critical energy released rate of the tested samples. 


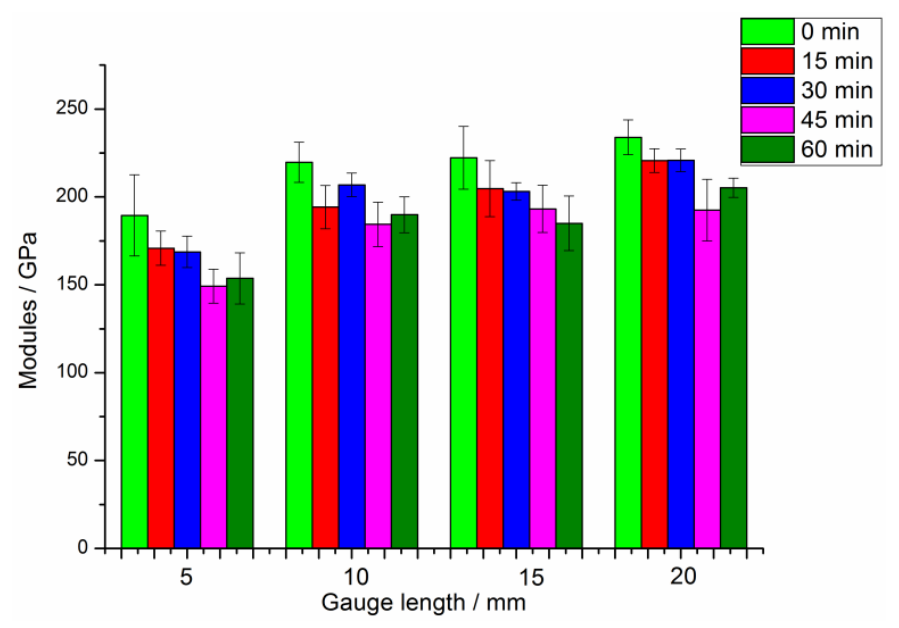

Figure 7 Longitudinal Young's modulus of carbon fibres before and after surface treatment

The critical energy released rate $G_{\text {Ic }}$ was calculated according to Equation 2 [8]; the obtained results are given illustrated in Figure 8. Although acid treatment always increases IFSS $_{a p p}$, the extent of this increase is sensitive to the treatment's duration. The energy release rate reached around $38.9 \mathrm{~J} \cdot \mathrm{m}^{-2}$ after $15 \mathrm{~min}$ of the surface treatment, dropping to $23.3 \mathrm{~J} \cdot \mathrm{m}^{-2}$ when the surface treatment time was extended to $30 \mathrm{~min}$. A high $G_{\text {Ic }}$ value implies a high energydissipation capacity in a fracture process at the epoxy/fibre interface. This study clearly demonstrated that the highest $G_{\text {Ic }}$ and the largest interface strength were not reached at the same treatment time.

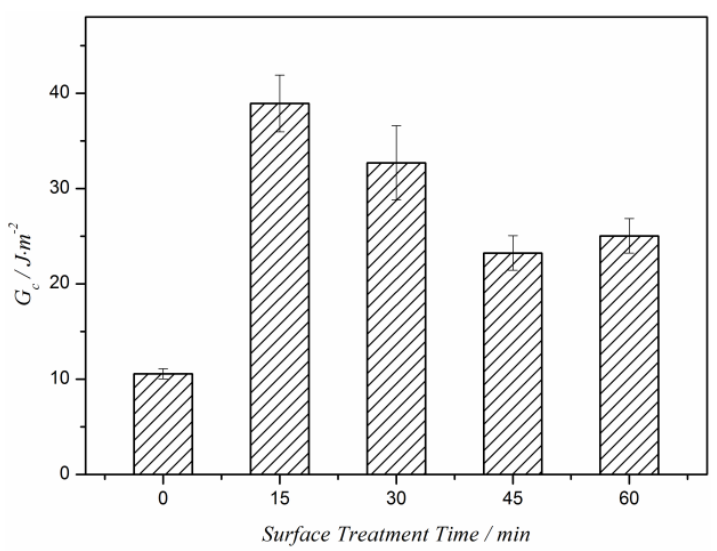

Figure 8 Effect of acid treatment time on critical energy release rate vs 


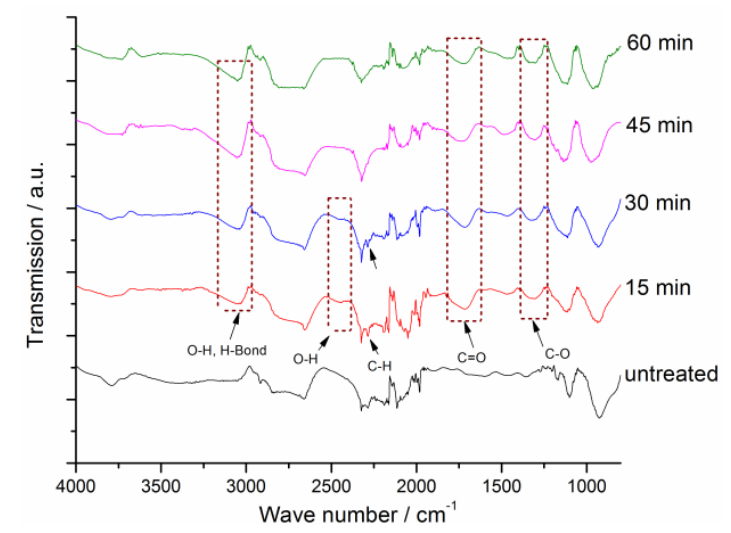

Figure 9 FTIR spectrums of A-42 carbon fibres before and after acid treatments of varying duration

The effect of surface treatment on the measured interface properties discussed above is mainly due to two aspects, viz, interface functionalization and surface morphologies. The obtained FT-IR spectra indicate the absence of hydroxyl -OH (3100-3300 $\left.\mathrm{cm}^{-1}\right)$ and carbonyl $-\mathrm{C}=\mathrm{O}$ groups $\left(1650-1740 \mathrm{~cm}^{-1}\right)$ in the carbon fibre after the acid treatment due to the formation of carboxyl -COOH groups [7, 20, 21], as shown in Figure 9. Besides, the characteristic bands due to generated polar functional groups were also observed in the spectrum of oxidised surface of carbon fibres. Specifically, mixed-acid oxidation introduces $\mathrm{OH}$, - $\mathrm{CH}-, \mathrm{H}-\mathrm{bond},-\mathrm{C}=\mathrm{O}$ and $\mathrm{C}-\mathrm{O}$ functional groups successfully on the fibre surface. The expected functional groups are illustrated in Figure 9. The -OH or - $\mathrm{COOH}$ groups are capable to form covalent interfacial bonds in the cross-linked polymer adhesive, which couple to the fibre, effectively transferring stresses between the matrix and the fibre and improving the interfacial adhesion [22, 23]. It was also reported that an increasing oxygen content after a surface treatment led to the improvement of interfacial shear strength. Furthermore, fracture toughness was improved by hydrogen and covalent bonding interaction [24]. Surface functionalization results in an increase in the polar component as well as the total surface free 
energy of the fibres. Therefore, the fibre/epoxy interface would present a higher energy barrier for crack initiation and propagation [25].

The surfaces morphologies of the specimens were further examined with AFM, as shown in Figure 10. The surface of untreated carbon fibres shows a number of relatively wide parallel grooves along their longitudinal direction. With an increase in the treatment time, large grooves were removed and the number of shallow grooves increased.. The likely cause of such grooves is the removal of amorphous carbon and defective layer on the border of fibrils forming a carbon fiber [26]. A removal of the outer layer may also eliminate strengthdegrading surface flaws. Therefore, tensile strength of carbon fibres increased after a moderate surface treatment. The evolution of the surface shown in Figure 10 is consistent with the obtained FE-SEM images. Table 2 shows that the average surface roughness (Ra) of CF increased from $2.40 \mathrm{~nm}$ to $4.15 \mathrm{~nm}$ with the treatment time. The moderate acid treatment made grooves wider and deeper. Etched pits were observed in some regions when surface treatment time reached $30 \mathrm{~min}$. After one hour of acid oxidation, the surface was significantly etched and damaged. On the one hand, these grooves and pits provide more bonding sites, increasing the interfacial adhesion. On the other hand, they introduce serious defects on the surface of carbon fibres, decreasing their tensile strength [15]. 


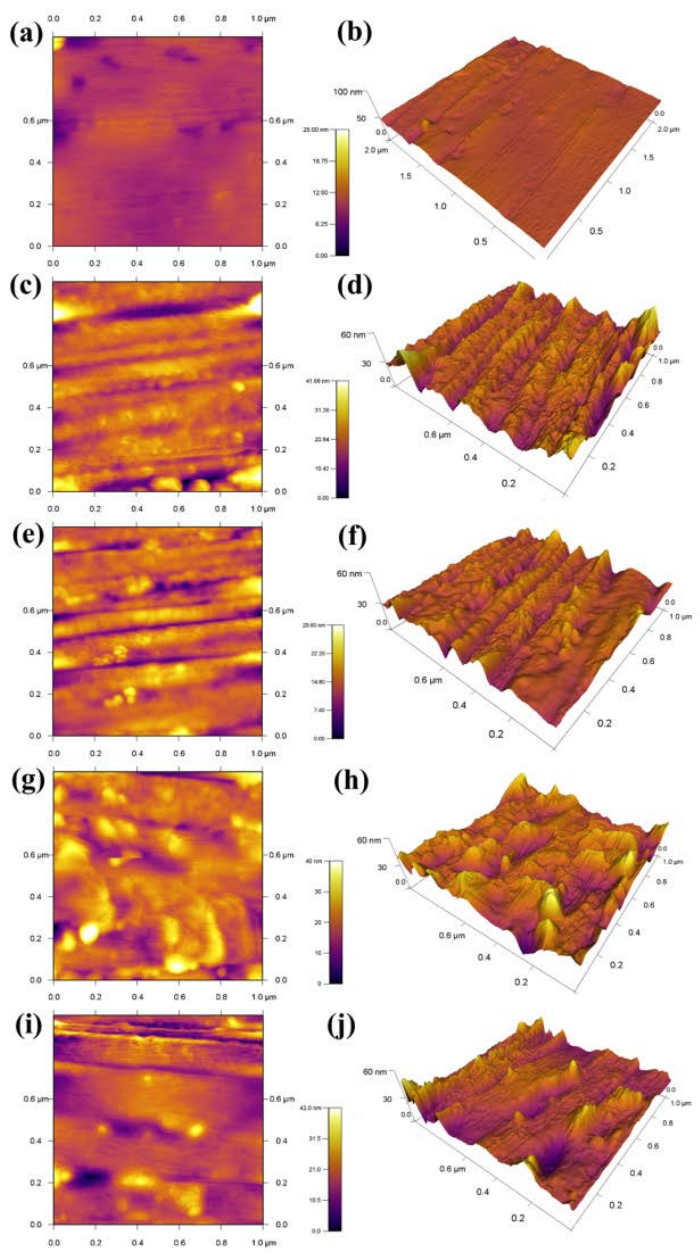

Figure 10 Surface morphology evolution of carbon fibre for various surface treatment times:

(a) 15 min; (b) 30 min; (c) 45 min; (d) 60 min (scan area: $1 \mu \mathrm{m} \times 1 \mu \mathrm{m}$ )

Table 2 Surface roughness of carbon fibres shown in Figure 10

\begin{tabular}{c|c|c}
\hline Treatment time (min) & Ra (nm) & RMS (nm) \\
\hline 0 & 2.40 & 3.27 \\
15 & 2.95 & 3.67 \\
30 & 3.43 & 4.94 \\
45 & 3.94 & 5.01 \\
60 & 4.15 & 5.77 \\
\hline
\end{tabular}



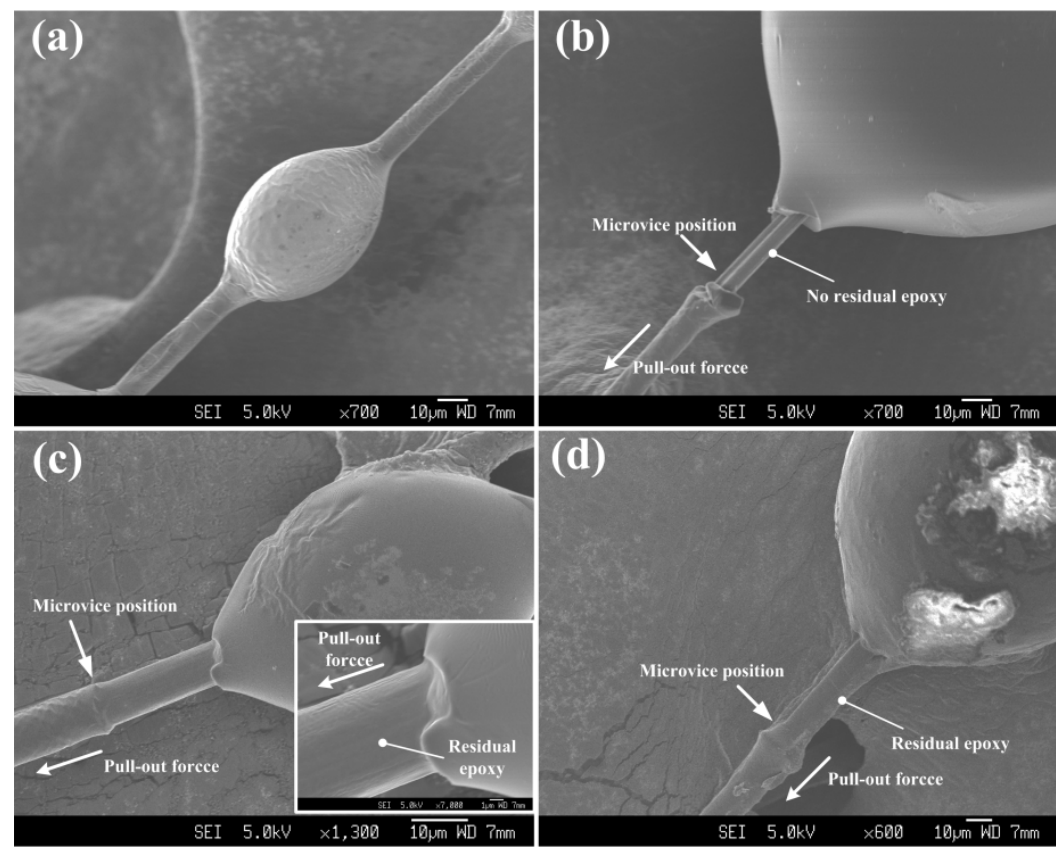

Figure 11 FE-SEM images of fibre/epoxy droplet system before (a) and after (b-d) microbond test. Surface treatment times are 0 min (b), 15 min (c) and 45 min (d), respectively

Post microbond test, samples were examined with FE-SEM to verify the location and mode of the failure. Figure 11(a) shows an undamaged fibre/epoxy droplet system prior to testing. For fibres without the surface treatment, interfacial separation was the main failure mode, indicative of poor adhesion (Figure 11(b)). There was no residual epoxy on the surface of fibres, which is a direct evidence of weak interface [27]. For fibres with the surface treatment, most of the droplets failed in a cohesive failure mode (Figure 11(c)). The failure occurred in the interphase region within the resin matrix but close to the fibre surface, i.e. where the shear stress reached maximum values during the microbond test. The presence of residual epoxy after debonding (Figure 11(c) and (d)) confirmed crack initiation in mode I in the droplet as a result of the radial normal stress distribution along the fibre-epoxy interface [23]. Drescher et al. [28] showed that a cohesive failure mode at interface provided better interfacial shear strength and fracture toughness due to surface interlocking and functional group bonding. However, when the interface bonding was too strong, fracture toughness decreased because 
debonding failure occurred in the matrix rather than at the cohesive interphase. This is in agreement with studies which claim that a weak interfacial bond dissipates more energy than a strong one and that micro-mechanisms such as fiber-matrix debonding or frictional fiber sliding are more important for energy absorption than macro-mechanisms such as delamination or matrix cracking under certain conditions [28, 29]. Apparently, for future applications, the energy dissipation capacity of various forms of CFRCs, such as woven and braided textile, can be enhanced by designing a suitable interfacial bond between the fibre filaments and the polymeric matrix.

\section{Conclusions}

The microbond test was used to evaluate interfacial properties between a single carbon fibre and an epoxy droplet. Alongside the apparent interfacial shear strength $I_{F S S_{a p p}}$, the interfacial fracture toughness was calculated in terms of the critical energy release rate $G_{\text {Ic }}$. The surface treatment was optimized by investigating the effects of its duration on $I F S S_{a p p}$ and $G_{\text {Ic }}$, as well as tensile strength of single filaments. Although interfacial adhesion improved with the increasing surface-treatment time, the interfacial fracture toughness was observed to peak at 15 min treatment based on the study conducted here. Surface roughening and functional group bonding may have played predominant roles in the enhancement of interfacial properties. Apparently, severe surface flaws were introduced by strong acid etching after a longer time of treatment (over $30 \mathrm{~min}$ ), resulting in a reduction of both filament's tensile strength and interfacial fracture toughness. From our study, the surface treatment time of 15 min was deemed optimal for an optimal improvement of both the strength and interfacial energy dissipation. The microscopic study indicated importance of the cohesive failure mode at interface for achieving high fracture toughness. 


\section{Acknowledgement}

$\mathrm{CW}$ is grateful for the financial support by NTU through the PhD scholarship award. The authors are grateful for the technical support by Dr Jinglei Yang and his research group at MAE, NTU, Singapore.

\section{References}

[1] Tatar Y, Ramazanoglu N, Camliguney AF, Saygi EK, Cotuk HB. The effectiveness of shin guards used by football players. J Sport Sci Med 2014; 13: 120-7.

[2] Kulkarni SG, Gao XL, Horner SE, Zheng JQ, David NV. Ballistic helmets- their design, materials, and performance against traumatic brain injury. Compos Struct 2013; 101: 313-31.

[3] Han SH, Oh HJ, Lee HC, Kim SS. The effect of post-processing of carbon fibers on the mechanical properties of epoxy-based composites. Compos Part B Eng 2013; 45: 172-7.

[4] Zhang G, Sun S, Yang D, Dodelet JP, Sacher E. The surface analytical characterization of carbon fibres functionalized by $\mathrm{H}_{2} \mathrm{SO}_{4} / \mathrm{HNO}_{3}$ treatment. Carbon 2008; 46: 196-205.

[5] Wang YB, Iqbal Z, Mitra S. Rapidly functionalized, waterdispersed carbon nanotubes at high concentration. J Am Chem Soc 2006; 128: 95-9.

[6] Xu CL, Chen JF, Cui Y, Han QY, Choo H, Liaw PK, Wu DH. Influence of the surface treatment on the deposition of platinum nanoparticles on the carbon nanotubes. Adv Eng Mater 2006; 8: 73-7.

[7] Yuan H, Wang CG, Zhang S, Lin X. Effect of surface modification on carbon fiber and its reinforced phenolic matrix composite. Appl Surf Sci 2012; 259: 288-93.

[8] Deng SH, Ma WD, Zhou XD, Fan CJ. Maintenance of highly interfacial shear strength by diblock copolymer between carbon fiber and epoxy resin in hostile environment. Compos Interfaces 2012; 19: 499-509.

[9] Gao X, Jensen RE, McKnight SH, Gillespie Jr JW. Effect of colloidal silica on the strength and energy absorption of glass fiber/ epoxy interphases. Compos Part A 2011; 42: 1738-47.

[10] Zhandarov S, Mäder E. Characterization of fiber/matrix interface strength: applicability of different tests, approaches and parameters. Compos Sci Technol 2005; 65: 149-60.

[11] Miller B, Muri P, Rebenfeld L. A microbond method for determination of the shear strength of a fiber/resin interface. Compos Sci Technol, 1987; 28: 17-32.

[12] Nairn JA. Analytical fracture mechanics analysis of the pull-ou test including the effects of friction and thermal stresses. Adv Compos Lett 2000; 9: 373-83.

[13] Liu CH, Nairn JA. Analytical fracture mechanics of the microbond test including the effects of friction and thermal stresses. Int J Adhesion Adhesives 1999; 9: 59-70.

[14] Scheer RJ and Nairn JA. A comparison of several fracture mechanics methods for measuring interfacial toughness with microbond tests. J Adhesion 1995; 53: 45-68.

[15] Langston TA, Granata RD. Influence of nitric acid treatment time on the mechanical and surface properties of high-strength carbon fibers. J Compos Mater 2014; 48: 259-76.

[16] Wang K, Li M, Liu YN, Gu YZ, Li QW, Zhang ZG. Effect of acidification conditions on the properties of carbon nanotube fibers. Appl Surf Sci 2014; 292: 469-74.

[17] Yu B, Jiang ZY, Tang XZ, Yue CY, Yang JL. Enhanced interphase between epoxy matrix and carbon fiber with carbon nanotube-modified silane coating. Compos Sci Technol 2014; 99: 131-40. 
[18] Sharma M, Gao S, Mäder E, Sharma H, Wei LY, Bijwe J. Carbon fiber surfaces and composite interphases. Compos Sci Technol 2014; 102: 35-50.

[19] Reynolds WN, Sharp JV. Crystal shear limit to carbon fibre strength. Carbon 1974; 12: 103-10.

[20] Park SJ, Seo MK, Ma TJ, Lee DR. Effect of chemical treatment of Kevlar fibers on mechanical interfacial properties of composites. J Colloid Interface Sci 2002; 252: 24955.

[21] Park SJ, Kim MH. Effect of acidic anode treatment on carbon fibers for increasing fibermatrix adhesion and its relationship to interlaminar shear strength of composites. $J$ Mater Sci 2000; 35:1901-5.

[22] Zhu J, Kim J, Peng H, Margrave JL, Khabashesku VN, Barrera EV. Improving the dispersion and integration of single-walled carbon nanotubes in epoxy composites through functionalization. Nano Lett 2003; 3: 1107-13.

[23] Liu Z, Jones FR, Zhai Z, Feng L. Interfacial Adhesion of polyamide 66 fibres to an aqueous polyurethane-acrylic hybrid polymer adhesive. J Adhesion 2014; 90: 310-26.

[24] Drzal LT, Madhukar M, Waterbury MC. Adhesion to carbon fiber surfaces: surface chemical and energetic effects. Compos Struct 1994; 27: 65-71.

[25] Ozkan T, Chen Q, Chasiotis I. Interfacial strength and fracture energy of individual carbon nanofibers in epoxy matrix as a function of surface conditions. Compos Sci Technol 2012; 72: 965-75.

[26] Chukov DI, Stepashkin AA, Gorshenkov MV, Tcherdyntsev VV, Kaloshkin SD. Surface modification of carbon fibers and its effect on the fiber-matrix interaction of UHMWPE based composites. J Alloy Compd 2014; 586: 459-63.

[27] Le Duigou A, Davies P, Baley C. Exploring durability of interfaces in flax fibre/epoxy micro-composites. Compos Part A: Appl S 2013; 48: 121-8.

[28] Drescher P, Thomas M, Borris J, Riedel U, Arlt C. Strengthening fibre/matrix interphase by fibre surface modification and nanoparticle incorporation into the matrix. Compos Sci Technol 2013; 74: 60-6.

[29] Tanoglu M, McKnight SH, Palmese GR, Gillespie Jr JW. The effects of glass-fiber sizings on the strength and energy absorption of the fiber /matrix interphase under high loading rates. Compos Sci Technol 2001; 61: 205-20. 